\title{
IV. Jatutizen.
}

Unverbrennbares holz.

$\mathfrak{3 m}$ Rowemberbeft 1897 bes Forftwirtífaftliden Sentralblattes 5.587 baben wir Ditteifung ïber einen am 9. Iugnft in Botba fattgefunbenen Berjud nit unverbrenn=

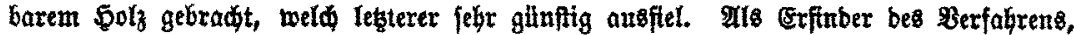

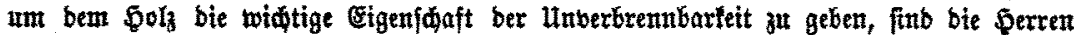
Brabley unb (Earier in New Vorl genannt.

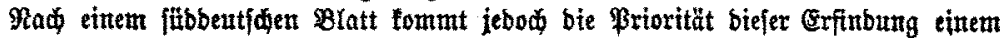

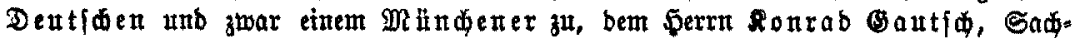

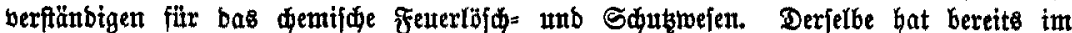
\$ahre 1882 bas \$roblem, Baulgolz bis auf ben \$ern abjolut feuerfeft za madien, voll=

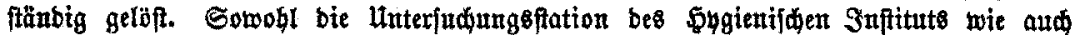
Profeffor Dr. Wittfein's demifdes \&aboratorium baben bamals bas bon (s)auti

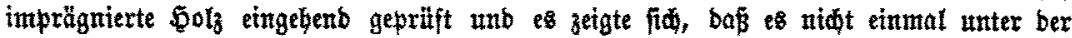

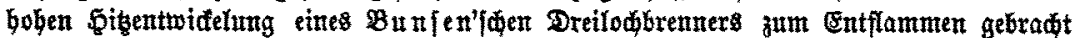
werben tonnte. Sn ber Mobellier = unb Sdinibfintle zu Dberammergan wurbe bas

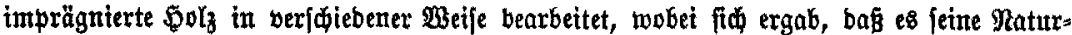
farbe beibebalten babe unb bis ins Snnere von Smprägnierftoff burdbrungen war, ohne

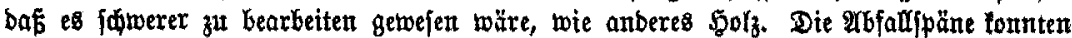
tridt zum Entzünben gebradt werben.

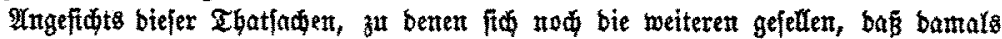

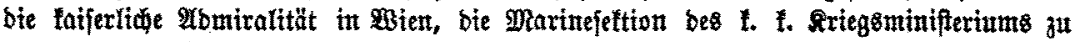

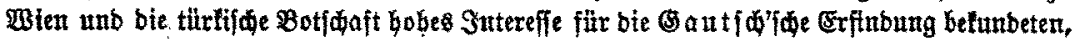

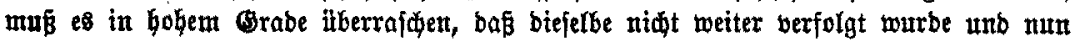
bie Ebre und ber materielle Erfolg berfelben Den eingangs genannten 5erren zufalfen.

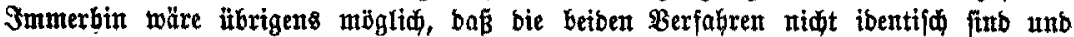

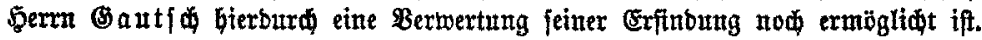

Rad einer uns mittferweile zugetommenen Broføitre nebft Muftern von unberbrent:

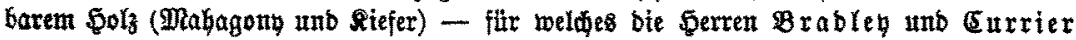
Patente in faft alfen Ränbern erworben baben - zeigt bas imprägnterte \$olz wie jenes

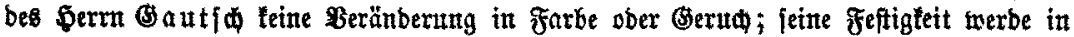

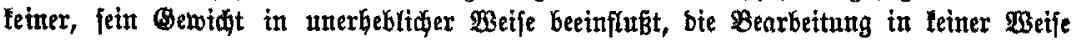
beeinträatigt. (5) witrb ferner mitgeteilt, baj in ben Bereinigten Stanten bas Wharite=

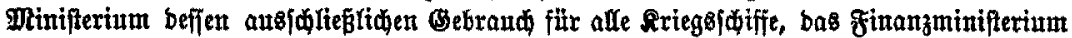
flir bie neu zat erridtenben offentlident (Gebänbe angeorbnet babe utb bas in zablretden

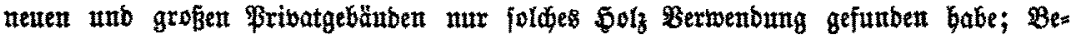

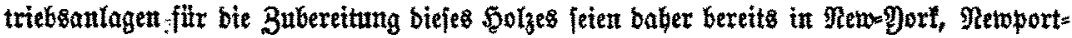

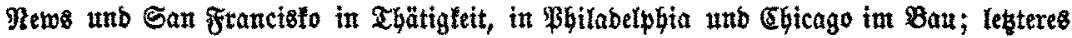
fei aud bereit in Englanb an mebreren Drten ber Fall, wie es benn aud eitr Eng=

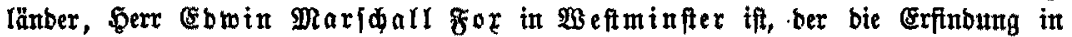

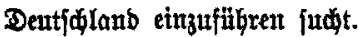

F.

Gุundeshagen = Stiftung.

4. Berzeidnis ber eingegangetten 8 eiträge.

Seit bem 11. Februar 1896 ftno unjerer Stiftung folgenbe Beiträge zugegangen: A. Beiträge von Brofefforen, Stubierenten umb Beamten ber Univerfttät Bießent. Brof. Dr. 2aiener $10 \ldots$, Prof. Dr. Sommer $5 \ldots$, \$rof. Dr. Strabl $10 \ldots$, 